\title{
Takayasu Arteritis: A Case Report
}

\author{
Harshini Kancherla*, Gayathri Konduri, Akhila Bollam, Keerthana Atla, Neelam Injeti \\ Department of Pharmacy Practice, CMR College of Pharmacy, Kandlakoya, Hyderabad, Telangana, INDIA.
}

\begin{abstract}
Takayasu arteritis is also known as pulseless disease and is an autoimmune disease with unknown etiology which is a rare type of chronic granulomatous vasculitis involving inflammation in the wall of the aorta and its main branches such as carotid, coronary, pulmonary and renal arteries. The left subclavian artery is the most frequently involved vessel. The disease can lead to narrowed artery walls that may tear, bulge and leads to pain in the chest, or arm, high blood pressure and eventually heart failure or stroke. It has a worldwide distribution, with the greatest prevalence in Asia. Women are affected in 80 to 90 per cent of cases, with an age of onset that is usually between 10 to 40 years. Stenosis of the renal artery has been reported in 23 to 31 per cent of cases and may result in malignant hypertension, ischemic renal disease, and decompensated heart failure. Involvement of both renal arteries is uncommon. A case study of 27-yearold female with symptoms like a blurred vision of the left eye, weakness,

syncopal attacks. Computerized tomography angiography shows Takayasu
\end{abstract}

arteritis with the early onset of anuria and acute kidney injury which were found very rare in the literature survey. The main complication of this case was Reno-vascular hypertension which was treated with T. Nicardia $\mathrm{XL} 30 \mathrm{mg}$ T. Arkamine $0.1 \mathrm{mg}$ Inj Labetalol $20 \mathrm{mg}$ and corticosteroids and immune suppressants were given to treat other complications.

Key words: Autoimmune disease, Granulomatous Vasculitis, Left renal artery stenosis, Renovascular hypertension, Takayasu arteritis.

\section{Correspondence}

Dr. Harshini Kancherla,

CMR College of Pharmacy, Kandlakoya, Medchal, Hyderabad-501401, Telangana, INDIA.

Email id: kancherlaharshini@gmail.com

DOI: 10.5530/jyp.2022.14.26

\section{INTRODUCTION}

Takayasu arteritis is also known as a pulseless disease is an autoimmune disease with unknown etiology which is a rare form of vasculitis involving inflammation in the wall of the aorta and its main branches. Epidemiologic investigation recommended that Takayasu arteritis is large progressively perceived in Europe with detailed occurrence varying from 0.4-1.5 per million. The prevalence of Takayasu arteritis in Japan is 40 per million and at least one 0.9 per million in the US. These varieties between the examinations might be gotten from topographical and hereditary contrast between the population. ${ }^{1}$

Pathogenesis of Takayasu arteritis remains unclear but a hypothesis state that gamma-delta lymphocytes, NK cells, and HSP65 protein play a critical role in vascular cell injury of Takayasu arteritis. ${ }^{2}$ Neurotic findings depend on aortic tissue test showed that gamma-delta $\mathrm{T}$ lymphocytes and NK cells are located in apoptosis of endothelial cells by the creation of perforin and killer cells lectin-like receptor subfamily K(NKG2D). The gamma-delta T lymphocyte and NK cells communicate with the NKG2D receptor and recognize MICA (Major histocompatibility class-1 chain receptor) on vascular smooth muscle and deliver perforin and cause inflammation. Proinflammatory cytokines are additionally delivered from $\mathrm{T}$ cells and induce the matrix metalloproteinases (MMPS) which leads to an inflammatory reaction in the vascular wall. ${ }^{3}$

Takayasu arteritis comprises 2 phases: an initial inflammatory phase which is characterised by fatigue, malaise, fever, night sweats, joint pains, weight loss, fainting. This stage may also be characterised by anaemia and elevated ESR and CRP. This phase is followed by the secondary pulseless phase characterised by dyspnea, palpitation, headache, rash, haemoptysis, ulceration, and weight loss. Other symptoms may include arm numbness, claudication in the legs, double vision, stroke, transient ischemic stroke, hemiplegia, and paraplegia. Vascular insufficiency from initial narrowing of the vessel leads to renal artery stenosis causing hypertension, and neurological manifestation due to decreased blood flow to the brain. This stage is followed by fibrosis and may be associated with the remission of symptoms. ${ }^{4}$

Takayasu arteritis can be assessed based on American college of rheumatology criteria as follows

1. Age at disease onset in year $<40$ years- Development of symptoms or findings related to Takayasu arteritis at age

2. Claudication of extremities- Defined as the development and worsening of fatigue, and discomfort in muscles of one or more extremities while in use, especially the upper extremity.

3. Decreased branchial artery- Decreased pulsation of one or both branchial arteries.

4. Blood pressure difference $>10 \mathrm{mmHg}$ - This difference is mainly seen in systolic blood pressure between the arms

5. Bruit over subclavian arteries or aorta- Bruit are audible on auscultation over one or both subclavian arteries or Abdominal aorta

6. Angiographic abnormality- Angiographic narrowing or occlusion of the entire aorta, its primary branches or large arteritis in the proximal branches or large arteritis in the proximal upper or lower extremities, not due to arteriosclerosis, fibromuscular dysplasia, or similar causes changes usually focal or segmental. ${ }^{5}$

\section{CASE DESCRIPTION}

A 27 years old female patient had a complaint of blurred vision in the left eye for 15 days for which she visited an ophthalmologist. Later she had 2-3 episodes of syncopal attack along with weakness of left lower limb for 3 days, proximal femur bone distal weakness, unable to walk. 
On physical examination, there was a remarkable blood pressure difference between the right arm and left arm. Her left arm BP was $140 / 90 \mathrm{mmHg}$ whereas her right arm BP was $150 / 90 \mathrm{mmHg}$ in a supine position with a pulse rate of 80 beats/min.

Cardiovascular examination reveals that:

1. Palpitation- Trachea in the midline, epical impulse in left $5^{\text {th }}$ Intercoastal pressure on the midclavicular line, No palpable murmurs.

2. Auscultation- Pulmonary area- Ejection systolic murmur heard not radiating to left carotid loud,

Aortic area Ejection systolic murmur $\mathrm{S}_{1} \mathrm{~S}_{2}$ heard.

\begin{tabular}{cc}
\hline Test & Value \\
\hline Complete blood picture & \\
WBC & Anisocytosis with hypochromic, \\
Platelet & normocytes and microcytes positive \\
Differential Count & Within the limit \\
Neutrophils & Mild thrombocytopenia \\
Lymphocytes & $87.3 \%$ \\
Complete urine examination & $11.7 \%$ \\
PUS Cells & Numerous calcium oxalate crystals \\
& are seen \\
Blood urea & $3-4 \mathrm{hpf}$ (Normal Range- 1-2/hpf) \\
Serum Creatinine & $48.97 \mathrm{mg} / \mathrm{dl}$ \\
Inflammatory Markers & $1.62 \mathrm{mg} \%$ \\
Erythrocyte sedimentation rate & $60 \mathrm{~mm} / \mathrm{hr}$ (Normal Range: Upto \\
C- Reactive protein & 20mm/hr) \\
Anti-nuclear antibody & $9.56 \mathrm{mg} / \mathrm{l}$ (Normal Range: less than \\
& 10mg/l) \\
& Borderline POSITIVE \\
ECG & Sinus rhythm, first-degree \\
& Atrioventricular block (AV block), \\
& LVH with repolarisation abnormality. \\
\hline
\end{tabular}

Her USG Abdomen reveals that 1) Retroperitoneum narrowed the calibre of the distal abdominal aorta. USG neck screaming done. Concentric wall thickening of right proximal CCA to consider the possibility of vasculitis. 2) Left kidney not visualised in the left renal fossa and ectopic sites. 2D Echo finding shows Concentric LVH, Grade-2 Diastolic dysfunction (DDF) normal Left ventricular (LV) Systolic function (EF-60\%). Fundoscopy reveals that B/L papilledema, Hard exudates positive, grade- 4 hypertension with retinopathy changes. MRI scan shows Multiple acute infarcts in the left frontotemporal, parietal lobe, caudate nucleus, right frontal lobe along the parasagittal plane, genu of the corpus callosum. Narrowing of MI segment of left Middle cerebral artery (MCA) with $40 \%$ stenosis of vessel. Narrowing of $\mathrm{A}_{3}, \mathrm{~A}_{4}$ of a left anterior cerebral vessel, hypoplasic left vertebral artery, right fetal Posterior cerebral artery (PCA). CT Angiography reveals that Left renal stenosis, Anterior cerebral artery (ACA) MCA narrowing distal aortitis, subclavian occlusion, B/L carotid occlusion, and right solitary kidney.

She was treated with Inj Labetalol 200mg IV, T. Aspirin $75 \mathrm{mg}$ OD, T. Atrovas 40mg HS, T.Clopitab $75 \mathrm{mg}$ OD, Inj Methylprednisolone $500 \mathrm{mg}$ in $100 \mathrm{ml}$ normal saline IV OD, T. Nicardia XL 300mg TID, T. Nodosis $500 \mathrm{mg}$ TID, T. Artemine $0.5 \mathrm{mg}$ OD, Her BP got stabilized by using this medication she was discharged from the hospital with medication i.e., T.Wysolone 30mg OD for 2 weeks, T. Folitrax $7.5 \mathrm{mg}$ OD on Sunday, T. Folinic acid 5mg a/d, T. Aspirin 75mg OD, T. Atrovas 40mg HS, T. Cardivas $3.125 \mathrm{mg}$ BD, T.Arkamine $0.1 \mathrm{mg}$ TID, T. Nicardia XL 30mg TID, Monitor for syncope.

\section{DISCUSSION}

Initially, the main aim of therapy, in this case, was to reduce ischemic complications and to treat hypertension. Based on her MRI findings the patient was diagnosed with a Cerebro-vascular accident with left hemiparesis and the treatment was started with T. Aspirin $75 \mathrm{mg}$, T. Clopitab 75mg T. Atrovas 40mg, T. Nicardia XL 30mg, T. Arkamine $0.1 \mathrm{mg}$, Inj Labetalol $20 \mathrm{mg}$ IV was prescribed to treat hypertension. As the USG abdomen scan revealed the possibility of vasculitis, so, Inj Methylprednisolone $500 \mathrm{mg}$ in $100 \mathrm{ml}$ NS were prescribed. It was stopped and replaced with T. Prednisolone $20 \mathrm{mg}$ on the same day of the afternoon. As the hypertension was not resolved, Inj Lasix $20 \mathrm{mg}$ was prescribed on next day. On the $2^{\text {nd }}$ day, Ejection systolic murmur in the aortic area radiating to carotid, ESM in pulmonary area, abdominal bruits+ same treatment was given. On day 3, the ANA profile revealed borderline positive. T. IFA was added and planned to start T. Methotrexate or T. Azathioprine. On day-4 same treatment was continued. On day $5 \mathrm{~T}$. Cardivas $3.125 \mathrm{mg}$ was added and planned to start T. Methotrexate $7.5 \mathrm{mg}$, on Sundays and T. Folic acid $5 \mathrm{mg}$ on alternate days. The same treatment was continued for 14days. On day 15 CT angiography was performed by this test they confirmed that the patient has Takayasu arteritis, and T. Prednisolone dose increased to $30 \mathrm{mg}$ for 2 weeks, T. Folitrax 7.5mg was given on every Sunday, T. Folic acid 5mg on an alternate day was prescribed. The patient was discharged on the $17^{\text {th }}$ day; the same medications were prescribed while discharge.

The treatment of Takayasu arteritis involves corticosteroids as firstline therapy, initiation of therapy with prednisolone $0.7-1 \mathrm{mg} / \mathrm{kg} /$ day for 1-3 months with gradual tapering once remission is obtained. ${ }^{6}$ At the initial stage of disease high dose of prednisolone is preferred but a replacement may occur while gradually decreasing the dose, so the physician will prefer immunosuppressants along with corticosteroids.? Similarly, in this case, immunosuppressants were prescribed along with corticosteroids for better treatment. Hypertension is usually worsened by the use of corticosteroids due to their fluid retaining property and ACE inhibitors, angiotensin receptor blockers are contraindicated in the presence of renal artery stenosis. ${ }^{8}$ In our case, ACE inhibitors and ARB are not preferred as they are contraindicated.

\section{CONCLUSION}

As Takayasu arteritis is a progressive vascular disease that may lead to many vascular complications and due to its higher chances of relapse, a long-term follow-up is important. Takayasu arteritis is mainly associated with cardiovascular complications, stroke, reno-vascular hypertension. Hypertensive urgency and stroke are the most serious complications which should be treated early. Early diagnosis and treatment help us to avoid the rapid progression of the disease.

\section{ACKNOWLEDGEMENT}

We thank Dr. I. Shyam Sunder Raju and Gandhi Hospital for his guidance and support.

\section{CONFLICT OF INTEREST}

The authors declare that there is no conflict of interest.

\section{ABBREVIATIONS}

NK Cells: Natural Killer Cells; HSP65: Heat Shock Protein65; MICA: Major Histo Compatibility Class-1 Chain receptor; MMPS: Matrix Metalloproteinases; ESR: Erythrocyte Sedimentation Rate; CRP: 
C-Reactive Protein; LVH- DDF: Diastolic dysfunction; LV: Left ventricular; MCA: Middle cerebral artery; PCA: Posterior cerebral artery; ACA: Anterior cerebral artery.

\section{REFERENCES}

1. Onen F, Akkoc N. Epidemiology of Takayasu arteritis. Presse Med. July-August 2017;46(7-8 pt 2):e197-203. doi: 10.1016/j.lpm.2017.05.034, PMID 28756072.

2. Seko Y, Minota S, Kawasaki A, Shinkai Y, Maeda K, Yagita $H$, et al. Perforinsecreting killer cell infiltration and expression of a 65-kD heat-shock protein in aortic tissue of patients with Takayasu's arteritis. J Clin Invest. 1994;93(2):750-8. doi: 10.1172/JCl117029, PMID 7906697.

3. Dominika P, Ratal P, David A, Piotor D. Takayasu arteritis- epidemiology, pathogenesis, diagnosis and treatment. J Appl Biomed;17:12-20.
4. Manfrini O, Bugiardini R. Takayasu's arteritis: A case report and a brief review of the literature. Heart Int. 2006;2(1):66. doi: 10.4081/hi.2006.66, PMID 21977253.

5. Arend WP, Michel BA, Bloch DA, Hunder GG, Calabrese LH, Edworthy SM, et al. The American College of Rheumatology 1990 criteria for the classification of Takayasu arteritis. Arthritis Rheum. 1990;33(8):1129-34. doi: 10.1002/ art.1780330811, PMID 1975175.

6. Keser G, Direskeneli H, Aksu K. Management of Takayasu arteritis: A systematic review. Rheumatology. 2014;53(5):793-801. doi: 10.1093/rheumatology/ket320. PMID 24097290.

7. Hoffman GS, Leavitt RY, Kerr GS, Fauci AS. The treatment of Wegener's granulomatosis with glucocorticoids and methotrexate. Arthritis Rheum. 1992;35(11):1322-9. doi: 10.1002/art.1780351113, PMID 1445449.

8. Lagneau P, Michel JB, Vuong PN. Surgical treatment of Takayasu's disease. Ann Surg. 1987;205(2):157-66. doi: 10.1097/00000658-198702000-00010, PMID 2880571.

Article History: Received: 13-12-2021; Revised: 23-12-2021; Accepted: 17-01-2022

Cite this article: Harshini K, Gayatri K, Akhila B, Keerthana A, Neelam I. Takayasu Arteritis: A Case Report. J Young Pharm. 2022;14(1):130-2. 